Andrew Bush ${ }^{1}$, 2 , lan D. Pavord ${ }^{3}$

a.bush@imperial.ac.uk

\title{
Review
}

\section{Challenging the paradigm: moving from umbrella labels to treatable traits in airway disease}

Airway diseases were initially described by nonspecific patterns of symptoms, for example "dry and wheezy" and "wet and crackly". The model airway disease is cystic fibrosis, which has progressed from nonspecific reactive treatments such as antibiotics for airway infection to molecular subendotype, proactive therapies with an unequivocal evidence base, early diagnosis, and biomarkers of treatment efficacy. Unfortunately, other airway diseases lag behind, not least because nonspecific umbrella labels such as "asthma" are considered to be diagnoses not mere descriptions.

Pending the delineation of molecular sub-endotypes in other airway disease the concept of treatable traits, and consideration of airway disease in a wider context is preferable. A treatable trait is a characteristic amenable to therapy, with measurable benefits of treatment. This approach determines what pathology is actually present and treatable, rather than using umbrella labels. We determine if airway inflammation is present, and whether there is airway eosinophilia which will likely respond to inhaled corticosteroids; whether there is variable airflow obstruction due to bronchoconstriction which will respond to $\beta_{2}$-agonists; and whether there is unsuspected underlying airway infection which should be treated with antibiotics unless there is an underlying endotype which can be addressed, as for example an immunodeficiency. The context of airway disease should also be extrapulmonary comorbidities, social and environmental factors, and a developmental perspective, particularly this last aspect if preventive strategies are being contemplated. This approach allows targeted treatment for maximal patient benefit, as well as preventing the discarding of therapies which are useful for appropriate subgroups of patients. Failure to appreciate this almost led to the discarding of valuable treatments such as prednisolone.

\section{Educational aims}

- To use cystic fibrosis as a paradigm to show the benefits of the journey from nonspecific umbrella terms to specific endotypes and sub-endotypes, as a road map for other airway diseases to follow.

- Demonstrate that nonspecific labels to describe airway disease can and should be abandoned in favour of treatable traits to ensure diagnostic and therapeutic precision.

- Begin to learn to see airway disease in the context of extrapulmonary comorbidities, and social and environmental factors, as well as with a developmental perspective.

@ERSpublications

Umbrella terms for airway disease like "asthma" should be replaced by "treatable traits" to target therapy, pending the discovery of specific endotypes https://bit.ly/2RTxS6I
Cite as: Bush A, Pavord ID Challenging the paradigm: moving from umbrella labels to treatable traits in airway disease. Breathe 2021; 17: 210053. 


\section{Introduction}

In "An Essay on Criticism", Alexander Pope wrote that:

"A little learning is a dangerous thing; Drink deep, or taste not the Pierian Spring: There shallow draughts intoxicate the brain, And drinking largely sobers us again."

(The first line is probably misquoted more often than any other piece of poetry, as "A little knowledge", which is quite another matter.) Airway disease has been in an era of intoxication and is perhaps emerging, but, as we will show, we have still got a lot of drinking to do before we see soberly.

A century ago, airway disease could crudely be divided into two: dry and wheezy, termed "asthma", and wet and crackly, the latter characterised by purulent secretions and chronic infection, often with digital clubbing, bronchiectasis, progressive respiratory failure, right heart failure ("cor pulmonale") and early death. This review charts the journey from these crude umbrella terms to where we are at in the 21st century; how in some airway diseases we are still at the little learning stage, whereas in others we have progressed to deep sober knowledge.

Lord Macauley, in the "Lays of Ancient Rome", describing Horatius holding the bridge, wrote:

"But hark! The cry is Astur:

And lo! The ranks divide;

And the great Lord of Luna

Comes with his stately stride"

Currently, when the ranks divide, it is personalised medicine that comes with stately stride: no talk or review is complete without it. But just as the Lord of Luna perished miserably, so should personalised medicine; the big modern quantum leap is beyond personalised medicine, rather moving from reactive to proactive medicine [1] Part of this entails recognising that a description is not a diagnosis.

\section{The "wet and crackly" umbrella: how have we progressed?}

\section{An exemplar journey out of the umbrella to proactive, molecular, sub-endotype based, individualised therapy: cystic fibrosis}

It is enlightening to consider how we have progressed with cystic fibrosis (CF). The first step was a pathological observation by Dorothy Andersen, in the 1930s, that some children dying of "wet airway disease", for want of a better term, had mucoviscidosis of the pancreas, and she used this term to describe the new disease [2]. We now know that $~ 15 \%$ CF patients have normal pancreatic function, but this does not detract from the value of her seminal observation. Diagnosis remained on autopsy until the 1950s, when an astute physician, Paul di Sant'Agnese, noted a large number of patients were admitted to hospital with heat exhaustion during a heat wave, and deduced this was due to loss of electrolytes in the sweat [3]. This led to the development of the sweat test. Again, we know now that some patients with CF have normal sweat electrolytes, but this was still a further significant step along the journey. Treatment improved but was reactive (treat infections with antibiotics, use physical methods to clear secretions) and largely one size fits all, and remained so until 1989 when the CF gene was localised to 7q31.2 [4-6] and was subsequently found to encode a protein, cystic fibrosis transmembrane conductance regulator (CFTR). CFTR has multiple functions, including chloride and bicarbonate transport, and modulation of the epithelial sodium transporter $\mathrm{ENaC}$ [7]. New functions are still being discovered, and more than 2000 CFTR mutations have been described [8].

The pathological significance of many of these mutations is still being worked out, but in the meantime, known disease-causing mutations have been placed into one of seven categories (table 1) [9]. Even this classification is imperfect; the commonest mutation, DF508, is conventionally a class II mutation, but is also unstable at the cell surface, hence also has class VI properties. Nonetheless, this classification has proved enormously valuable in deploying new therapies. The US CF Foundation financed a robotic high-throughput system to screen thousands of compounds rapidly, and the first discovery was VX-770 (ivacaftor, Kalydeco), which was initially shown to increase the efficiency of chloride transport in class III mutations (G551D being the exemplar). The results were dramatic: sweat chloride halved, weight was gained, spirometry rose in absolute terms by $\sim 15 \%$, and quality of life improved [10]. Subsequently, VX-770 was shown to be effective in those gene classes where abnormal CFTR reached the cell surface, for example the class IV mutation R117H [11]. Crucially, it is entirely useless if there is no significant quantity of CFTR at the cell surface (classes I, II and VII), so if it had been given to all CF patients it would probably have been discarded as ineffective. The next step was to develop compounds that could rescue the misfolded protein, resulting from class II mutations, allowing it to reach the cell surface, and then deploying VX-770 to improve efficiency of action. These endeavours culminated in triple therapy [12, 13], Trikafta, for DF508, homo- and heterozygotes, which had the same dramatic effects as VX-770 in G551D. A key step has been doing large, definitive randomised controlled trials, for 
Table 1 The different molecular sub-phenotypes of cystic fibrosis

\begin{tabular}{|c|c|c|c|}
\hline Mutation class & Defect & Exemplar mutations & Corrective therapy \\
\hline I & $\begin{array}{l}\text { Premature stop codon leading to } \\
\text { a truncated transcript which is } \\
\text { destroyed }\end{array}$ & G542X, W1282X & $\begin{array}{l}\text { None available, compounds which override } \\
\text { premature termination codons being explored } \\
\text { Candidate for gene therapy }\end{array}$ \\
\hline II & $\begin{array}{l}\text { Abnormal protein is synthesised } \\
\text { but destroyed, not trafficked to cell } \\
\text { membrane }\end{array}$ & DF508 & $\begin{array}{l}\text { Corrector-potentiator combinations, e.g. } \\
\text { Trikafta }\end{array}$ \\
\hline III & Impaired anion conductance function & G551D & The potentiator ivacaftor \\
\hline IV & Decreased channel opening time & $\mathrm{R} 117 \mathrm{H}$ & The potentiator ivacaftor \\
\hline $\mathbf{V}$ & $\begin{array}{l}\text { Less CFTR protein reaches the cell } \\
\text { surface }\end{array}$ & $3849+10 \mathrm{~kb} C>\mathrm{T}$ & $\begin{array}{l}\text { Splicing correctors when available, possibly } \\
\text { ivacaftor }\end{array}$ \\
\hline VI & $\begin{array}{l}\text { Protein is abnormally unstable at the } \\
\text { cell surface }\end{array}$ & c.120del23 & Promote stability when medications available \\
\hline VII & No mRNA produced & $1717-1 G->A$ & $\begin{array}{l}\text { No therapies available } \\
\text { Candidate for gene therapy }\end{array}$ \\
\hline
\end{tabular}

Note that mutations may fall into more than one subcategory. For example, DF508, a class II mutation, is also unstable at the cell surface (class VI).

which the CF community already had a great track record, to robustly demonstrate efficacy. No-one is interested in a meta-analysis or systematic review of these trials because the originals are definitive. In parallel, another key component of progress was the early and objective diagnosis of CF (newborn screening), so new medications will in the future prevent lung damage rather than merely ameliorate established disease.

But with success came fresh problems, which again are being overcome:

- How can regulators be convinced that these medications are useful in those with very mild disease and normal spirometry?

- How can regulators be convinced that these medications are effective in very young children who cannot cooperate with physiological testing?

- How can we show efficacy in patients with very rare mutations, or those of dubious significance?

- As other companies bring variants of these new molecules into the market, how will we work out which molecule is best for which patient?

One answer has been the development of physiological end-points, which are much more sensitive than spirometry. For example, multiple breath washout (MBW), which requires only passive cooperation and thus can be used in young children $[14,15]$. This technique is abnormal in many with normal spirometry. MBW has been accepted as a valid trial end-point [16]. For young infants, all that has been required is evidence of safety and efficacy as shown by a big reduction in sweat chloride, with no requirement for improvement in respiratory physiological end-points [17]. This approach can also be used for rare mutations, a group in whom large randomised controlled trials are unfeasible.

Finally, and most excitingly, in vitro systems have been devised so the effects of medications on ion transport can be assessed on an individual patient basis. This can be done using cells harvested by nasal brushing [18], or more usually in Europe, with organoids [19]. Organoids are generated from tissue obtained by suction rectal biopsy, for which no anaesthesia is required. In vitro the tissue forms spheroids, with the rectal luminal side internal. Stimulation of CFTR in an organoid from a normal subject leads to it swelling; this response is absent in CF, and can be restored by appropriate biologicals. The response in organoids correlates with individual in vivo response to the medication [19], potentially giving a system in which multiple medications can be quickly tested to make the best choice for the individual. It can also be used to determine if rare gene variants of uncertain significance will respond.

So, in summary, in 80 years CF has gone from being lost in a mass of chesty children to a disease with molecular, sub-endotype proactive specific therapies, which can be chosen on an individual basis from an in vitro test. This progress has been combined with early diagnosis through newborn screening, which means the near future will not be chronically sick children, but well children whose disease manifestations have largely been abrogated by starting individualised medication soon after birth. It should be noted that almost every step on the journey was subsequently shown to be imperfect in some way, but this did not halt progress. The CF journey (box 1) should be aspirational and inspirational for all other airway diseases, albeit 
Box 1 The road to progress in airway disease, based on the CF paradigm. It is depressing to contemplate how little progress has been made in the asthmas.

- Understand the fundamental science.

- Use this knowledge to develop designer molecules, to move from reactive to proactive medicine.

- Find biomarkers predicting and monitoring therapeutic/drug efficacy.

- Carry out the definitive randomised trials in all age groups.

- Ensure early and specific diagnosis with objective tests.

more testing in polygenic conditions with a major contribution from environmental factors.

\section{Other wet, crackly diseases}

The number of cases of "idiopathic" bronchiectasis is shrinking as different disease entities are being teased out. None has come as far as CF, which has the advantage of being a monogenic disease (albeit a complex one). Other exemplars are primary ciliary dyskinesia (PCD), and the systemic immunodeficiencies. Knowledge of ciliary biophysics and PCD genetics is increasing exponentially, and it is surely only a matter of time before gene specific treatments are deployed, for example for disease caused by premature termination codons. Specific treatments are being discovered for genetic sub-endotypes of immunodeficiency, such as anti-interleukin (IL)-6 strategies (tocilizumab and sarilumab), and the JAK inhibitors ruxolitinib, baricitinib, tofacitinib and upadacitinib for GATA-2 mutations [20]. Less specific approaches such as stem cell or bone marrow transplantation may be curative. The overall direction of travel is to pull specific entities with specific treatments out from under the "wet, crackly" umbrella, and further exciting developments are to be anticipated. In summary, a description (bronchiectasis, which is a wet cough, sputum, infection and inflammation) is not a diagnosis or a basis for starting a highly specific therapy. What is needed is clear recognition of the mechanism of the associated clinical problem, the identification of clinically accessible biomarkers, and targeted treatment.

\section{The "dry, wheezy umbrella": where are we now?}

\section{The story of the "asthmas"}

Wheeze and chest tightness, and the use of the term "asthma", were first described in antiquity [21]. Although the existence of separate "asthmas" was long suspected based on clinical characteristics (for example, wheeze for a few days in a schoolchild in the allergy season versus late middle aged persistent symptoms [22]), real progress was only made in the late 1950s by the late, very great Harry Morrow-Brown, an adult chest physician in Derby, UK. He was astonished by the conclusion of a Medical Research Council trial that prednisone was not helpful in asthma. He used his medical school microscope to look at sputum and demonstrated that prednisone was only useful in patients with eosinophilic sputum, not neutrophilic [23]. The same was true for inhaled beclomethasone (BDP). Thus, this early experiment in personalised medicine salvaged two of the most effective treatments for any known disease. Unfortunately, in the rush to prescribe BDP, which was transformative for many, the lesson of the need to match the right treatment to the right patient was lost. Subsequently, mepolizumab was studied in poorly selected asthma patients and was also nearly discarded [24], until a series of trials in asthmatic patients with sputum eosinophilia and recurrent acute attacks demonstrated unequivocal benefit [25-27].

The term "asthma" proved to be a somewhat two-edged sword. There was unequivocal benefit in the use of the label when it prevented children with inhaled corticosteroid (ICS)-responsive airway disease being fobbed off with unnecessary antibiotics, and meant that acute attacks of breathlessness were managed efficiently with prednisone and bronchodilators [28]. However, confusion arose from definitions conflating clinical symptoms, abnormal spirometry findings and assumed pathological descriptions, and meaningless questions such as "at what age can asthma be diagnosed?" [29] abounded, without thought as to what "asthma" actually meant.

The Lancet Asthma Commission [30] has sought to clarify this, by insisting that asthma is a clinical syndrome, comprising wheeze, breathlessness, chest tightness and sometimes excessive cough. Just as the patient given the nonspecific label of "arthritis" would instantly respond "what sort of arthritis?", so the diagnosis of asthma should prompt the question "what sort of asthma are we talking about?". In order to answer this question the airway needs to be deconstructed into its components, with a specific focus on what is treatable, and subsequently, what treatment success will look like. For airway disease, these components are as follows.

- Fixed airflow obstruction: this trait is not treatable, but awareness that it is present will prevent over-treatment, trying to reverse the irreversible. Its identification might also focus attention on strategies that reduce the future rate of decline in airflow obstruction.

- Variable airflow obstruction: there are many causes, including airway smooth muscle constriction, mucus plugging and airway malacia and instability, but if the child or adult with asthma has the treatable trait of $\beta_{2}$ agonist-responsive bronchoconstriction, then 
short-acting (SABA) and possibly long-acting (LABA) $\beta_{2}$-agonists should be prescribed.

- Airway inflammation: this may be beneficial (as a normal airway defence against infection) or adverse; and if present may be neutrophilic, eosinophilic or mixed. If, and only if, the child or adult with asthma has the treatable trait of eosinophilic airway inflammation, then ICS are indicated. Wheeze of itself is not a reason to prescribe ICS nor can tests of variable airflow obstruction reliably identify this process.

- Airway infection: may be obvious, as in CF (discussed earlier), or more difficult to diagnose. If the treatable trait of bacterial airway infection is present, then antibiotics, and where appropriate mucolytics and airway clearance techniques, should be prescribed. Investigation for immunodeficiency and other causes, such as aspiration syndromes may be appropriate.

- Mucus hypersecretion without bacterial infection being present may be another treatable trait, managed by airway clearance techniques augmented with exercise.

The treatable trait approach extends beyond the airway; the airways should not be considered in isolation, but as part of extrapulmonary comorbidities, social and environmental factors [31], and a developmental perspective [32]. The main focus of this review is on the airway, but social factors such as adherence and environmental factors such as active and passive smoking are also important [33, 34].

There are numerous causes of airflow obstruction (table 2) and the treatable trait approach allows holistic and individualised care. No-one would suggest that the treatment of CF and obliterative bronchiolitis should be the same, even though both exhibit fixed airflow obstruction. The approach also cuts through frequently asked, but wholly meaningless questions, such as "at what age can you diagnose asthma?" or "are patients born preterm more likely to get asthma?". In adults we have "is this asthma or COPD?", a question that roughly translates as "should we offer poorly targeted empirical treatment for one largely arbitrary condition or another?". The important questions, irrespective of age or attendant comorbidities, are: "Does this patent have eosinophilic airway inflammation which is thus likely to respond to ICS?"; and "Are there other treatable traits making an important contribution to the patient's problems?".

The same approach works in chronic suppurative lung disease; if a patient with CF or bronchiectasis has airway eosinophilia in addition to chronic infection and neutrophilic inflammation, then treatment with ICS or even mepolizumab is appropriate [35]. Unfortunately, ICS are often used without regard to the airway phenotype [36], often because wheeze is equated with asthma which is equated with "need for ICS prescription". Over-prescription of ICS arises because: 1) the noises parents describe as wheeze may, in fact, not be the classic polyphonic expiratory noises, but something quite different and often nonspecific [37-39]; and 2) true wheeze is not the same as bronchospasm, and may be caused, for example, by intraluminal mucus.

\section{How should this work: preschool wheeze?}

Traditionally the preschool years have been a black hole in terms of any testing, because the children are too old to sedate and too young to cooperate. Initially preschool children were classified based on symptoms as episodic viral wheeze or multiple trigger wheeze, with the former being treated intermittently as needed and the latter with continuous therapy if symptom severity merits it [40]. One problem with this classification is that it relies on parental perception of symptoms. Next the suggestion was made that severity of attacks, not pattern of symptoms, should drive regular treatment [41]. This too is illogical, because if attacks respond then all should be treated and if not, severity is not a reason for fruitless treatment. Atopy was also proposed as a useful biomarker [42], but it has become very clear that there is only the loosest relationship between symptom patterns, and the presence or otherwise of either or both of atopy and eosinophilic airway inflammation [43]. The first attempt to personalise treatment was the INFANT study [44], which recruited 300 preschoolers aged $1-5$ years and in a cross-over design, evaluated their response to regular ICS, as needed ICS and montelukast, also measuring allergic sensitisation and peripheral blood eosinophil count. In a pre-specified analysis, those who were sensitised showed a differential response to ICS. Post hoc, a combination of allergic sensitisation and blood eosinophils $\geq 300$ cells per $\mu \mathrm{L}$ predicted ICS responsiveness. If the INFANT study is confirmed prospectively, two simple tests can be used to personalise therapy in this hitherto challenging age group. In support of this, in a small study of preschool children with severe wheeze, we showed that there was good agreement between bronchoalveolar lavage (BAL) and peripheral blood eosinophil count [45].

However, although the INFANT study was a big step forward, much is still lacking. Even in the sensitised, eosinophilic group, although outcomes are greatly improved, they still are imperfect. We do not know the molecular endotypes, would anti-T-helper cell (Th)2 strategies, such as omalizumab and mepolizumab, be beneficial? Or another biological such as anti-IL-33? Of even more concern, we do not understand the molecular pathways initiating the development of wheeze. Initially the argument was that ICS are excellent treatment of eosinophilic asthma, so starting treatment early, in the pre-eosinophilic phase, would prevent asthma developing. Three excellent randomised controlled trials of early ICS torpedoed 


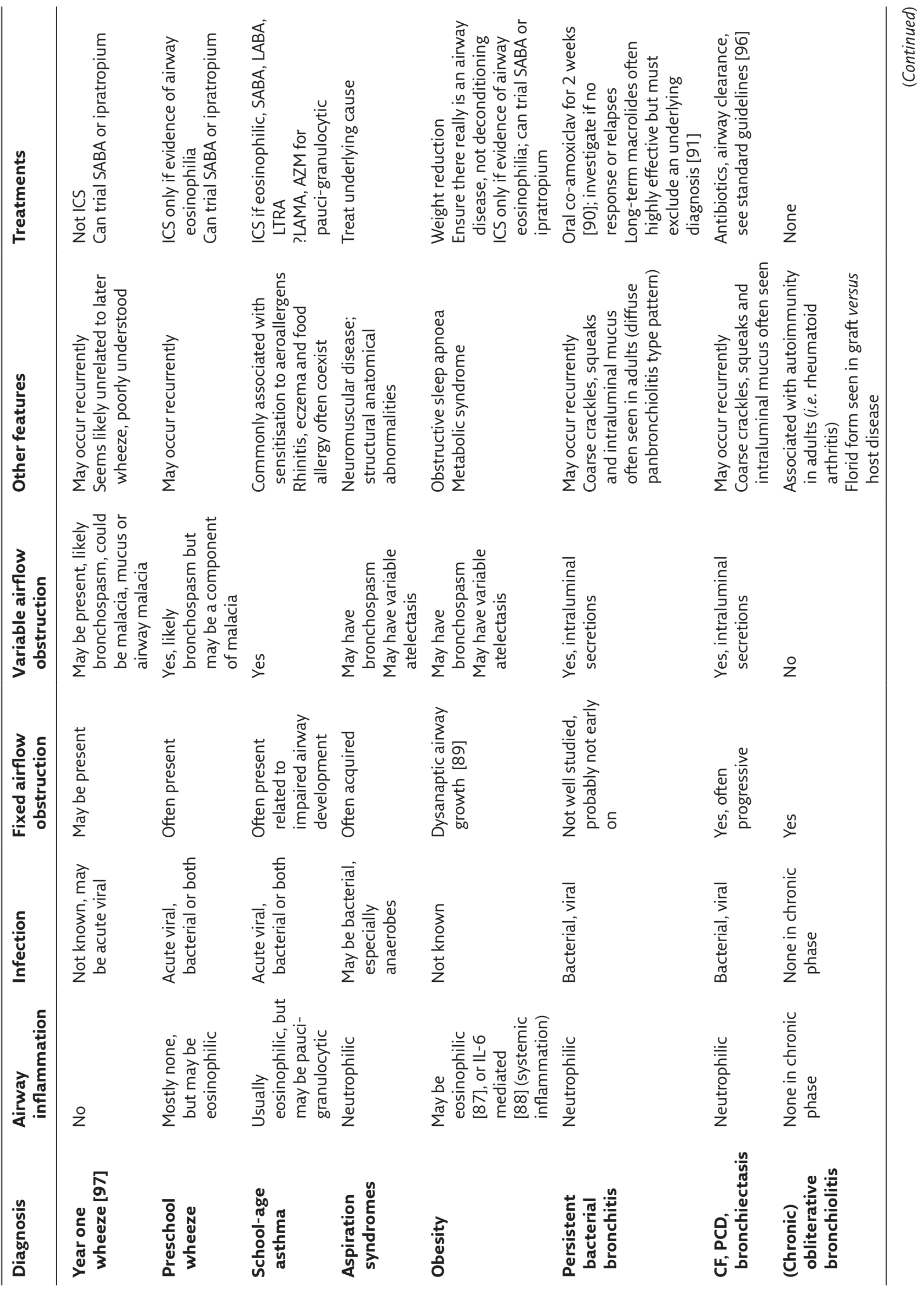




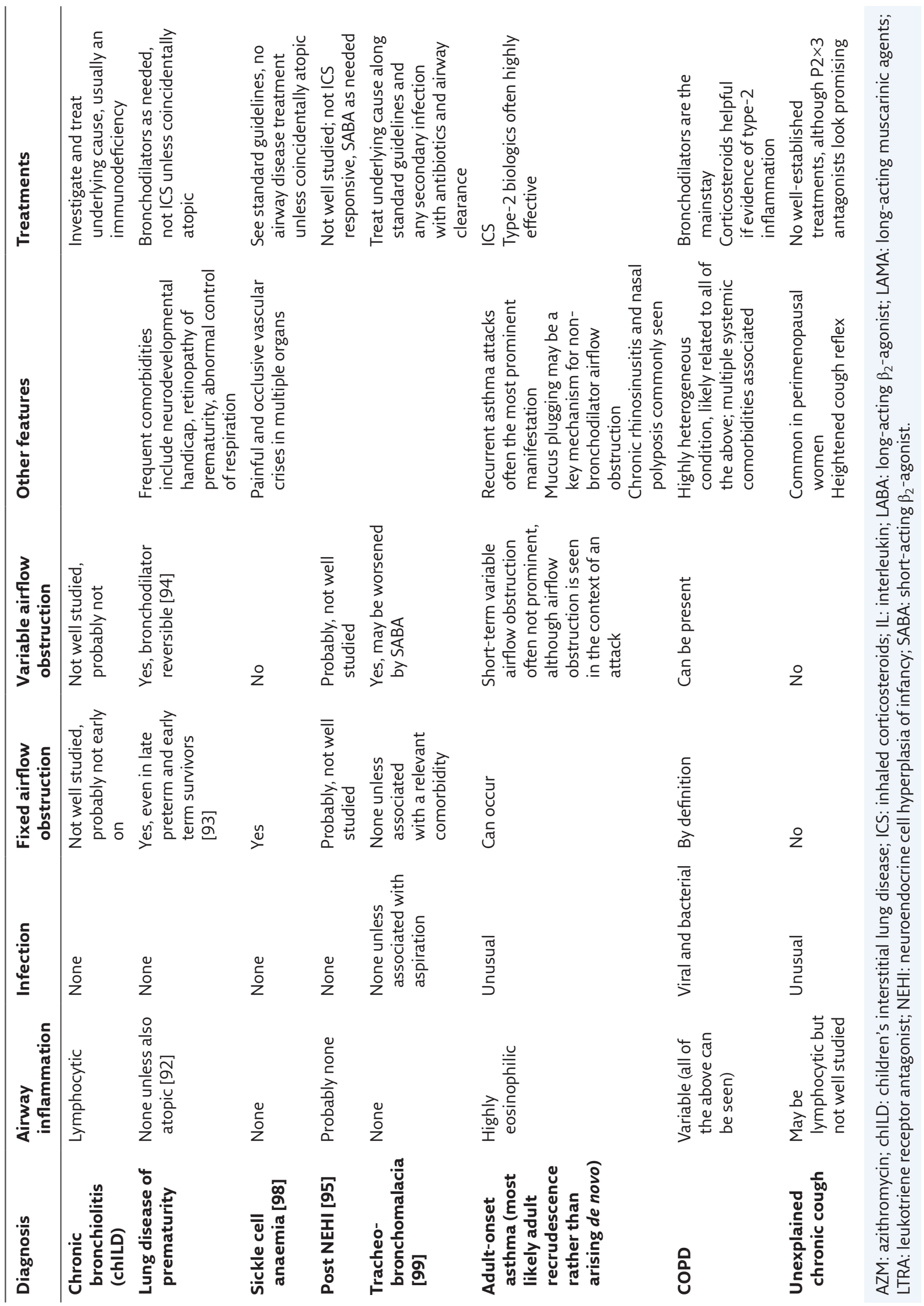


this notion [46-48], and when science caught up [49, 50], it was clear that eosinophilic inflammation was a late comer, and symptoms started in the absence of inflammation. So it was no surprise that early ICS did not prevent the development of wheeze, or modulate disease progression. That something can be done is clear; the genetically almost identical Amish and Hutterites, who respectively use traditional and modern farming methods, have very different asthma and atopy outcomes, with outcomes being much better in the Amish [51]. This may be related to environmental lipopolysaccharide exposure. There are tantalising hints of the importance of bacteria; early nasopharyngeal bacterial colonisation is associated with increased wheeze and worse respiratory outcomes in childhood [52], and bacterial oral immunotherapy may also reduce wheeze attacks [53]. We have yet to reach even the first step in box 1 .

\section{How should this work: school-age airway disease?}

The standard assumption is that school-age asthma is easily diagnosed, a disease related to atopy, is characterised by airway eosinophilia and responds to low-dose ICS, and for many children with mild-to-moderate disease this is true. Over- and under-diagnosis is frequent in children and adults largely because of the unwillingness to deploy simple objective tests such as measurements of physiology (peak flow, spirometry) and eosinophilic inflammation (sputum eosinophil count, exhaled nitric oxide $\left(F_{\mathrm{ENO}}\right)$ ) [54-56]. However, in those with a clearly established diagnosis who have been rendered symptom and attack free by low doses of safe, simple medications, the priority for endotyping is probably low, although understanding the differences between this type of asthma and severe asthma (discussed later) may be illuminating. However, some children and adults have a pauci-inflammatory picture, and do not respond to ICS [57]. We have no understanding of the pathophysiology of this condition, nor how to treat it, and in the case of many treating asthma, no realisation that the condition even exists. Longacting muscarinic agents (LAMA) and macrolides may be indicated $[58,59]$, but this is another area where there is a shameful lack of paediatric data. In our hands at least, and by contrast with adult studies [60], neutrophilic intra-epithelial inflammation is associated with better not worse outcomes [61]. What is clear in the school-age asthmas is that if the child is not responding to low-dose medications, the answer is not to escalate treatment, at least in the first instance, but instead to carry out a detailed, protocolised evaluation [62]. There is no evidence that ICS doses above $200 \mu \mathrm{g} \cdot$ day $^{-1}$ bring any additional benefit to most children [63].

With appalling complacency, we have settled for palliative care, as stressed in the Lancet commission [30], even in the eosinophilic asthmas. We are content to paper over the cracks with ICS, without even considering the possibility of trying to switch off the underlying disease progress. By analogy, we have thrown a life belt to a drowning man, but shown no interest in pulling him out of the water! The real reason, therefore, for needing much more molecular information about "well-controlled" asthma is to stop the disease in its tracks, and reverse the adverse long-term respiratory outcomes, in particular COPD $[64,65]$. Part of this is understanding fixed airflow obstruction, which is present in many children with asthma from an early age [66], and tracks into late middle age, and for which we have no therapies. That something may be able to be done is hinted at by the catch-up growth seen in those with delayed puberty [67]. No-one would suggest this is a good strategy therapeutically, but it does serve as a corrective against therapeutic nihilism. Even more importantly, persistent airflow limitation is associated with increased and premature all-cause morbidity and mortality [68]. It is likely that systemic and respiratory outcomes have the same underlying cause rather than being causally related, but could probing the endotypes of airflow obstruction lead to pathways to improving more than just respiratory outcomes? Finally, there is a strong trans-generational relationship between parental and offspring spirometry [68], and we do not know the basis for this or how to break this cycle. In summary, we need to be shaken out of our complacency about fixed airflow obstruction in childhood, irrespective of whether the child has "asthma" or whether any "asthma" is controlled by ICS.

\section{How should this work: adult airway disease?}

In adults there are complex dimensions to the "asthmas". First, environmental and treatment related factors and patient growth modify the relationships between triggers, pathology and disease expression. There is also an important developmental perspective. A minority of adults with severe asthma have an apparently adultonset non-allergic phenotype, typically associated with nasal polyposis, blood eosinophilia, marked eosinophilic airway inflammation and a great response to biologics targeting type- 2 cytokines. However, prevention of this phenotype may need to start very early on. The Tucson group showed that those with asthma of apparently adult onset in fact had evidence of airway disease at age 6 years [69], and even occupational asthma [70], which par excellence would seem to be a purely adult disease, is more common in those with early life adverse socioeconomic and environmental factors. Hence a key airway disease message, highlighted by the Lancet commission [30], is the need for us to leave our "paediatric" and "adult" silos and interact so a true developmental perspective can be taken. 
COPD and the conceptually bizarre [71, 72] Asthma-COPD Overlap Syndrome (ACOS) are both diagnosed in adult life, although again, the roots are antenatal and in the preschool years. Both are characterised by persistent airflow obstruction. Again, the pertinent question is: "Does this adult have eosinophilic airway inflammation and is thus likely to respond to ICS?", and this is much more important than labels. The concept of ACOS has been strongly criticised, and adult studies have shown that "COPD" with peripheral blood eosinophilia responds to what are more conventionally considered asthma medications, such as corticosteroids or anti-type- 2 inflammation biologicals such as mepolizumab $[73,74]$.

\section{How should this work: severe asthma?}

In adult severe asthma this approach has been the catalyst for a period of rapid progress [75]. The recognition that eosinophilic type-2 airway inflammation is an important and readily recognisable treatable trait in severe asthma associated particularly with asthma attacks has been key. There are now five biological agents targeting this mechanism available for use in the clinic [76] and we are achieving results that we could hardly have dreamed of 10 years ago. The use of regular oral corticosteroids, the most common therapeutic intervention offered by UK severe asthma centres in 2010 [77], has been confined to the therapeutic dustbin, and the burdensome adverse effects associated with this treatment are becoming a dim distant memory. A particular feature of treatment with biologics is that simple, clinically accessible biomarkers (blood eosinophils and $F_{\mathrm{ENO}}$ ) are highly predictive of the impact of treatment, meaning that we are able to offer these treatments in a targeted way, with failure rates that are a half of those seen with non-targeted biologics in other conditions such as rheumatoid arthritis. Our ability to demonstrate that high-cost biologics are used efficiently has made it much easier to build robust economic cases for approval from regulatory authorities such as the UK National Institute for Health and Care Excellence (NICE). Stratification based on mechanisms has also highlighted much more clearly what the unmet need is and treatable traits driving non-type- 2 mechanisms are beginning to be discovered [78, 79]. However, it remains the case that greater understanding of endotypes is needed in order to move treatment on from suppression to cure; and that we are devoid of any effective treatments for non-type 2 severe asthma. The majority of patients in adult severe asthma clinics would not have been eligible to be recruited into the randomised controlled trials of type 2 biologics [80].

Clarity of endotypes is urgently needed in paediatric severe asthma. Three major studies have demonstrated the heterogeneity of the condition [81-83]. The SARP network [81] recruited 53 asthmatic children (of whom 31 had severe asthma), and 30 adult controls (it is obviously very difficult ethically to obtain paediatric control data). Univariate analysis was unhelpful in differentiating moderate from severe asthma, so they used linear discriminant analysis. Analysing BAL IL-6 and IL-13 differentiated asthma from controls; CXCL1 (GRO), RANTES (CCL5), IL-12, interferon (IFN)- $\gamma$ and IL-10 were the five cytokines which differentiated severe from moderate asthma and controls. Alveolar macrophage lysate analysis showed IL-6 was the best discriminant. The authors concluded that severe asthma was neither Th1 nor Th2 predominant.

The Brompton paediatric study [82] recruited 104 children with putative severe, therapy resistant asthma (STRA), of whom 51 were not studied further because they were found not to be therapy resistant. There were 16 controls, largely with upper airway disease or undergoing a general anaesthetic for another purpose. These 69 children, mean age 11.8 years, underwent fibreoptic bronchoscopy, BAL and endobronchial biopsy. Those children with STRA had significantly increased BAL fluid and endobronchial biopsy eosinophil counts compared with controls. The STRA children exhibited marked between-patient variability in eosinophilia. Despite the marked eosinophilia in many patients, there was a paucity of evidence of type 2 cytokine expression. There was no increase in BAL fluid IL-4, IL-5, or IL-13 levels in patients with STRA compared with controls, and only rarely were these cytokines detected in induced sputum. Immunohistochemistry showed that biopsy IL-5 and IL-13 positive cell counts were similar in STRA patients and controls. Hence the evidence of type 2 inflammation in these children was very weak.

The third study was even more challenging [83]. 52 STRA children provided 68 BAL samples, there were no mild/moderate asthmatic or normal controls. The first important finding was that infection with either or both of viruses and bacteria were common; yet antibiotic therapy rarely impinges on our current therapeutic mindset. From a cross-sectional study confounded by the fact that treatment could not be stopped for obvious reasons, it is not possible to determine whether these pathogens were related to the asthma phenotype or secondary to topical mucosal immunosuppression by highdose ICS. BAL was enriched by CCR5 positive Th1 cells. They also detected pro-inflammatory (GM-CSF, IL-1 $\beta$, IL-6, IL-33, MIP3 $\alpha$, tumour necrosis factor (TNF)- $\alpha$ ), Th1 (IFN- $\gamma$, IL-12p70, IL-27, IL-28A), Th2 (IL-4, IL-5, IL-9, IL-13, IL-31) and Th17 (IL-17A, IL-17F, IL-23) cytokines in BAL. Th2 skewing correlated with total serum $\operatorname{lgE}$, and those who were poly-sensitised had increased IL-5, IL-33 and IL-28A/IFN $\lambda 2$. It was clear that not all allergens were equal; Th2 
skewing correlated with slgE to house dust mite, ryegrass and fungi, but not to cat, ragweed and food allergens. Only BAL IL-5 increased with age and correlated with BAL and blood eosinophils. Of course, correlation and cause are not the same thing, and causation cannot be determined from a cross-sectional study that is confounded by the effects of treatment.

To summarise, it is clear that much more work is needed on endotyping this really severe group, and thus rationalising treatment. We must get beyond the current position of throwing treatments haphazardly at these needy children.

\section{Where next: from phenotype to endotype}

The concept of the treatable trait of airway eosinophilia has been a huge step forward. However, the question of stability of this trait arises. One useful definition of a phenotype (which is what a treatable trait can be considered as) is the set of observable characteristics or traits of an organism that are produced by the interaction of the genotype and the environment. Clearly phenotyping must result in useful action or it is a pointless exercise. However, if the environment changes, then so may the phenotype, and this is crucial. For example, a 10-year-old boy with atopic asthma if untreated will have airway eosinophilia. ICS are prescribed and taken efficiently, so he no longer has this trait. Subsequently he stops his ICS and the trait returns, disappearing again when he recommences therapy. He is cat allergic, and his family are foolish enough to import three pet cats into his home, so back comes his eosinophilia until the cats are taken out of the environment, and/or the ICS dose is increased. He then gets a viral lower respiratory tract infection and becomes transiently neutrophilic. The underlying molecular pathway, or endotype (defined as a subtype of a condition, which is defined by a distinct functional or pathobiological mechanism), has not changed, but the manifestation of that endotype changes with the environment. Thus, it is unsurprising that there have been studies showing instability of sputum cellular and molecular phenotypes in both children [84, 85] and adults [86]. Of course, this does not at all discredit the concept, but underscores the need for regular critical re-appraisal of treatment.

The inevitable imprecision of phenotypes is one reason to progress to endotypes, but more pressing is the increasing array of biologicals becoming available. Currently, the licensed options in paediatrics are limited to omalizumab (binds circulating $\operatorname{lgE}$ ) and mepolizumab (binds IL-5), both of which have been spectacularly successful treatments in school-age children and adults, but alternative strategies will soon become an option (table 3 ). It should be noted that the lack of data in young children, and the lack of much enthusiasm for doing these studies, is in stark contrast to the situation in CF. It is also conceivable that a combined strategy that blocks all three signature type 2 cytokines (IL-4, IL-5 and IL-13) may be needed in some children. It could, at least hypothetically, be the case that the eotaxins or the epithelial alarmins might drive airway eosinophilia in some cases, independent of type 2 pathways, or that other mechanisms exist. Thus in a U-BIOPPRED study of adults, sputum transcriptomic, Affymetrix array and proteomics on induced sputum identified three cellular clusters [97]: the first characterised by blood and sputum eosinophilia, with underlying type 2 inflammation; a second cluster, which was neutrophilic, with IFN and TNF expression; and a third in which there was mild eosinophilia or no inflammatory cells, associated with metabolic and mitochondrial gene upregulation, but not type 2 inflammation even if eosinophilia was present. Of note, these clusters were not particularly stable over time [86].

Table 3 Potential biologicals for treatment of severe paediatric asthma

\begin{tabular}{|c|c|c|c|}
\hline Biological & Mode of action & Licensing status (UK) & Indications \\
\hline Omalizumab & $\begin{array}{l}\text { Binds IgE preventing binding to the } \\
\text { high-affinity IgE receptor (FceRI) on } \\
\text { mast cells and basophils } \\
\text { May also have antiviral effects }\end{array}$ & Age 6 years and over & $\begin{array}{l}\text { IgE between } 30 \text { and } 1300 \mathrm{IU} \cdot \mathrm{mL}^{-1} \\
\text { (In the UK) } \geq 4 \text { prednisolone bursts per year, } \\
\text { aeroallergen sensitised, adherent to standard } \\
\text { therapy } \\
\text { Dose depends on weight and IgE levels }\end{array}$ \\
\hline Reslizumab & Binds circulating IL-5 & Not licensed & Not applicable \\
\hline Benralizumab & Binds IL-5 receptor & Not licensed & Not applicable \\
\hline Dupilumab & Binds IL-4/IL-13 receptor & Age 12 years and over & Only licensed for atopic eczema \\
\hline
\end{tabular}




\section{The future: where from here?}

A long and painful journey has meant that the "asthmas" have reached only just beyond where Harry Morrow-Brown took us in the 1950s. The phenotypes are more specific, but we have yet to discern the molecular sub-endotypes discovered in CF. We have specific therapies, mainly directed at type 2 inflammation, but as yet do not know which agent is best for which eosinophilic patient. We have only very nonspecific therapies for non-eosinophilic asthma in the older child, such as LAMA and macrolide antibiotics. We have not done the big trials in children.

Where next? Discovering the specific endotypes of the asthmas has to be the top priority, followed by targeting existing or new biologicals to the endotype. We must not repeat the mistakes of the past and use a scattergun therapeutic approach, risking discarding valuable therapies. Next must come biomarkers of these endotypes and also treatment response. Ideally these would be from breath analysis, but futuristically, could it be that constructing an in vitro airway model using cells obtained from nasal brushing on a chip becomes possible, with the ability to model interactions with the patient's own blood cells?

One huge, as yet, unsolved problem is the cost of these powerful new biologicals. The existing CF and asthma biologicals are priced well beyond the healthcare budgets of low- and middle-income settings, and it is unlikely that future ones will be any cheaper. Spiralling healthcare costs are not an issue that will go away any time soon, but a solution is urgent to avoid discrimination against the patients in the poorest countries.

Whatever route we take in airway disease, it is essential to keep the road map so dramatically traced by the monogenic disease CF in mind. CF has certainly led the way, but there is no reason why the asthmas cannot follow; this is an exciting time to be a young investigator! But the very first step is to acknowledge our present and past mistakes, and that there is an important road to be travelled.

\section{Self-evaluation questions}

1. Which statement is true of the treatment of the sub-endotypes of CF? Select one correct answer.

a) Currently five molecular sub-endotypes of CF have been described

b) Ivacaftor is exclusively used to treat class III gating mutations

c) Ivacaftor cannot be used in preschool children because they are so well that there is no useful clinical end-point of efficacy

d) Tissue from rectal biopsy can be used to predict treatment responses to the novel biological therapies

2. Which statement(s) about asthma are correct? Select all that are correct.

a) Asthma is a disease characterised by eosinophilic airway inflammation

b) Type 2 inflammation usually but not always underlies airway eosinophilia

c) Chronic infection is a feature of some cases of severe asthma

d) No biomarkers for eosinophilic airway inflammation are applicable to preschool children

3. Bronchodilator-responsive variable airflow obstruction is seen in which of the following disease(s)? Select all that are correct.
a) Uncomplicated sickle cell anaemia
b) Adult survivors of chronic lung disease of prematurity
c) Preschool wheeze
d) Uncomplicated post-adenovirus obliterative bronchiolitis

4. In which of the following should consideration be given to seeing if the treatable trait of eosinophilic inflammation is present? Select one correct answer.
a) COPD
b) Bronchiectasis
c) $\mathrm{CF}$
d) All of the above

5. Which of the following may be the underlying mechanism of variable airflow obstruction? Select all that are correct.
a) Large airway malacia
b) Intraluminal mucus
c) Bronchial carcinoid
d) Airway smooth muscle constriction

\section{Key points}

- We need to follow the paradigm of CF and move from nonspecific reactive (antibiotics for purulent infected secretions, mucolytics) agents to proactive, molecular sub-endotype driven therapies with biomarkers of efficacy.

- Umbrella terms such as "asthma" and "chronic obstructive lung disease" need to be replaced by the concept of treatable traits to guide treatment.

- The treatable traits approach is applicable to all airway diseases and allows individualised treatment.

- ICS should be reserved for airway diseases characterised by airway eosinophilia, irrespective of age, umbrella label or the presence of comorbidities. 


\section{Affiliations}

\section{Andrew Bush ${ }^{1,2}$, Ian D. Pavord}

1Paediatrics and Paediatric Respirology, Imperial Centre for Paediatrics and Child Health, Imperial College London, London, UK. ${ }^{2}$ Royal Brompton and Harefield NHS Foundation Trust, London, UK. ${ }^{3}$ Respiratory Medicine, Respiratory Medicine Unit and Oxford Respiratory NIHR BRC, Nuffield Dept of Medicine, University of Oxford, Oxford, UK.

A. Bush and I.D. Pavord are Emeritus NIHR Senior Investigators.

\section{Conflict of interest}

A. Bush has nothing to disclose. I.D. Pavord reports other from Aerocrine AB (speaker fees), other from Almirall (speaker fees, consultant fees), other from AstraZeneca (speaker fees; payments for organisation of educational events; consultant fees; international scientific meeting sponsorship), other from Boehringer Ingelheim (speaker fees; consultant fees; international scientific meeting sponsorship), grants and other from Chiesi (speaker fees; consultant fees; international scientific meeting sponsorship; research grant), other from GSK (speaker fees; payments for organisation of educational events; consultant fees; international scientific meeting sponsorship), other from Novartis (speaker fees; consultant fees), other from Regeneron Pharmaceuticals, Inc (speaker fees; payments for organisation of educational events; consultant fees; international scientific meeting sponsorship), other from Sanofi (speaker fees; payments for organisation of educational events; consultant fees; international scientific meeting sponsorship), other from Teva (speaker fees; payments for organisation of educational events; consultant fees; international scientific meeting sponsorship), consultant fees from Circassia, Dey Pharma, Genentech, Knopp Biosciences, Merck, MSD RespiVert and Schering-Plough, and other from Napp Pharmaceuticals (consultant fees; international scientific meeting sponsorship), all outside the submitted work.

\section{References}

1. Bush A. Onward and upward: beyond personalized medicine to proactive medicine. Paediat Aller Imm Pul 2020; 33: 124-126.

2. Andersen $\mathrm{DH}$. Cystic fibrosis of the pancreas and its relation to celiac disease: a clinical and pathological study. Am J Dis Child 1938; 56: 344-349.

3. Di Sant'Agnese PA, Darling MD, Perera G, et al. Abnormal electrolyte composition of sweat in cystic fibtrosis and relationship to disease. Pediatrics 1953; 12: 549-563.

4. Rommens JM, lannuzzi MC, Kerem B, et al. Identification of the cystic fibrosis gene: chromosome walking and jumping Science 1989; 245: 1059-1065.

5. Kerem B, Rommens JM, Buchanan JA, et al. Identification of the cystic fibrosis gene: genetic analysis. Science 1989; 245 1073-1080.

6. Riordan JR, Rommens JM, Kerem B, et al. Identification of the cystic fibrosis gene: cloning and characterization of complementary DNA. Science 1989; 245: 1066-1073.

7. Haq IJ, Gray MA, Garnett JP, et al. Airway surface liquid homeostasis in cystic fibrosis: pathophysiology and therapeutic targets. Thorax 2016; 71: 284-287.

8. Cystic Fibrosis Foundation, Johns Hopkins Medicine. CFTR2 website. https://cftr2.org/

9. De Boeck K, Amaral MD. Progress in therapies for cystic fibrosis. Lancet Respir Med 2016; 4: 662-674.

10. Ramsey BW, Davies J, McElvaney NG, et al. A CFTR potentiator in patients with cystic fibrosis and the G551D mutation. N EnglJ Med 2011; 365: 1663-1672.

11. Pilewski JM, De Boeck K, Nick JA, et al. Long-term ivacaftor in people aged 6 years and older with cystic fibrosis with ivacaftor-responsive mutations. Pulm Ther 2020; 6 303-313.

12. Davies JC, Moskowitz SM, Brown C, et al. VX-659-tezacaftorivacaftor in patients with cystic fibrosis and one or two Phe508del Alleles. N EnglJ Med 2018; 379: 1599-1611.

13. Middleton PG, Mall MA, Dřevínek P, et al. Elexacaftortezacaftor-ivacaftor for cystic fibrosis with a single Phe508de Allele. N EnglJ Med 2019; 381: 1809-1819.
14. Aurora P, Bush A, Gustafsson P, et al. Multiple breath washout as a marker of lung disease in preschool children with cystic fibrosis. Am J Respir Crit Care Med 2005; 171: 249-256.

15. Lum S, Gustafsson P, Ljungberg $\mathrm{H}$, et al. Early detection of cystic fibrosis lung disease: multiple-breath washout vs. raised volume tests. Thorax 2007; 62: 341-347.

16. Davies J, Sheridan H, Bell N, et al. Assessment of clinical response to ivacaftor with lung clearance index in cystic fibrosis patients with a G551D-CFTR mutation and preserved spirometry: a randomised controlled trial. Lancet Respir Med 2013; 1: 630-638.

17. Rosenfeld M, Cunningham S, Harris WT, et al. An open-label extension study of ivacaftor in children with CF and a CFTR gating mutation initiating treatment at age $2-5$ years (KLIMB). J Cyst Fibros 2019; 18: 838-843.

18. Pranke I, Hatton A, Masson A, et al. Might brushed nasal cells be a surrogate for CFTR modulator clinical response? Am J Respir Crit Care Med 2019; 199: 123-126.

19. Ramalho AS, Fürstová E, Vonk AM, et al. Correction of CFTR function in intestinal organoids to guide treatment of cystic fibrosis. Eur Respir J 2021; 57: 1902426.

20. Silva-Carmona M, Vogel TP, Marchal S, et al. Successful treatment of interstitial lung disease in STAT3 gain-of-function using JAK inhibitors. Am J Respir Crit Care Med 2020; 202: 893-897.

21. Rosner F. Moses Maimonides' treatise on asthma. Thorax 1981; 36: 245-251

22. Rackemann FM. A clinical survey of 1074 patients with asthma followed for two years. J Lab Clin Med 1927; 12 : 1185-1197.

23. Brown HM. Treatment of chronic asthma with prednisolone; significance of eosinophils in the sputum. Lancet 1958; 2 : 1245-1247.

24. Leckie MJ, ten Brinke A, Khan J, et al. Effects of an interleukin-5 blocking monoclonal antibody on eosinophils, airway hyperresponsiveness, and the late asthmatic response. Lancet 2000; 356: 2144-2148. 
25. Nair P, Pizzichini MMM, Kjarsgaard M, et al. Mepolizumab for prednisone-dependent asthma with sputum eosinophilia. N EnglJ Med 2009; 360: 985-993

26. Haldar P, Brightling CE, Hargadon B, et al. Mepolizumab and exacerbations of refractory eosinophilic asthma. N Eng/J Med 2009; 360: 973-984.

27. Pavord ID, Korn S, Howarth P, et al. Mepolizumab for severe eosinophilic asthma (DREAM): a multicentre, double-blind, placebo-controlled trial. Lancet 2012; 380: 651-659.

28. Speight N, Pearce SJ. Asthma in children. Br Med J (Clin Res Ed) 1984; 289: 185-186.

29. Bush A, Pavord ID. "We can't diagnose asthma until <insert arbitrary age>". Arch Dis Child 2018; 103: 729-731.

30. Pavord ID, Beasley R, Agusti A, et al. After asthma: redefining airways diseases. Lancet 2018; 391: 350-400.

31. Agusti A, Bel E, Thomas M, et al. Treatable traits: toward precision medicine of chronic airway diseases. Eur Respir J 2016; 47: 410-419.

32. Bush A. Impact of early life exposures on respiratory disease. Pediatr Respir Rev 2021; in press [https://doi.org/10.1016/j. prrv.2021.05.006].

33. Hedlin G, Bush A, Lodrup Carlsen K, et al. Problematic severe asthma in children, not one problem but many: a GA2LEN initiative. Eur Respir J 2010; 36: 196-201.

34. Bracken $M B$, Fleming $L$, Hall $P$, et al. The importance of nurse led home visits in the assessment of children with problematic asthma. Arch Dis Child 2009; 94: 780-784.

35. Carpagnano GE, Scioscia G, Lacedonia D, et al. Severe uncontrolled asthma with bronchiectasis: a pilot study of an emerging phenotype that responds to mepolizumab. J Asthma Allergy 2019; 12: 83-90.

36. Dehlink E, Richardson C, Marsh G, et al. Are inhaled corticosteroids prescribed rationally in primary ciliary dyskinesia? Eur Respir J 2018; 51: 1702221.

37. Cane RS, Raganathan SC, McKenzie SA. What do parents of wheezy children understand by "wheeze"? Arch Dis Child 2000; 82: 327-332.

38. Cane RS, McKenzie SA. Parents interpretation of children's respiratory symptoms on video. Arch Dis Child 2001; 84: 31-34.

39. Elphick HE, Sherlock P, Foxall G, et al. Survey of respiratory sounds in infants. Arch Dis Child 2001; 84: 35-39.

40. Brand PL, Baraldi E, Bisgaard H, et al. Definition, assessment and treatment of wheezing disorders in preschool children: an evidence-based approach. Eur Respir J 2008; 32: 1096-1110.

41. Brand PL, Caudri D, Eber E, et al. Classification and pharmacological treatment of preschool wheezing: changes since 2008. Eur RespirJ 2014; 43: 1172-1177.

42. Castro-Rodriguez JA, Rodrigo GJ. Efficacy of inhaled corticosteroids in infants and preschoolers with recurrent wheezing and asthma: a systematic review with metaanalysis. Pediatrics 2009; 123: e519-e525.

43. Robinson PFM, Pattaroni C, Cook J, et al. Lower airway microbiota associates with inflammatory phenotype in severe preschool wheeze. J Allergy Clin Immunol 2019; 143: 1607-1610.

44. Fitzpatrick AM, Jackson DJ, Mauger DT, et al. Individualized therapy for persistent asthma in young children. J Allergy Clin Immunol 2016; 138: 1608-1618.

45. Jochmann A, Artusio L, Robson K, et al. Infection and inflammation in induced sputum from preschool children with chronic airways diseases. Pediatr Pulmonol 2016; 51: 778-786.

46. Guilbert TW, Morgan WJ, Zeiger RS, et al. Long-term inhaled corticosteroids in preschool children at high risk for asthma. N Engl J Med 2006; 354: 1985-1997.

47. Murray CS, Woodcock A, Langley SJ, et al. Secondary prevention of asthma by the use of inhaled fluticasone dipropionate in wheezy Infants (IWWIN): double-blind, randomised controlled study. Lancet 2006; 368: 754-762.

48. Bisgaard $\mathrm{H}$, Hermansen $M N$, Loland L, et al. Intermittent inhaled corticosteroids in infants with episodic wheezing. N Engl J Med 2006; 354: 1998-2005.

49. Saglani S, Malmstrom K, Pelkonen AS, et al. Airway remodeling and inflammation in symptomatic infants with reversible airflow obstruction. Am J Respir Crit Care Med 2005; 171: 722-727.

\section{Suggested answers}

1. a) False: there are seven classes. b) False: ivacaftor is used to treat class IV mutations, and in combination with other biologicals, class II mutations. c) False: sweat chloride reduction is accepted as a surrogate for efficacy of ivacaftor in young well children. d) True: organoids are generated and swelling in vitro is a good marker of restoration of activity of $\mathrm{CF}$ transmembrane activator.

2. a) False: asthma is a clinical syndrome of wheeze, chest tightness, breathlessness and cough, and although there may be airway inflammation, there are non-inflammatory phenotypes. b) True: although non-Th2 pathways are described, most eosinophilic asthma is driven by type 2 cytokines (IL-4, IL-5, and IL-13). c) True: a positive bacterial culture is found in some cases of severe asthma, although whether causative is unknown. d) False: peripheral blood eosinophil count and aeroallergen sensitisation are useful pointers to preschool eosinophilic airway inflammation in children with preschool wheeze seen in secondary care.

3. a) False: there is fixed airflow obstruction unless there is coincident atopy, in which case variable airflow obstruction is present. b) True. c) True. d) False: there is fixed airflow obstruction unless there is coincident atopy, in which case variable airflow obstruction is present.

4. d) All three diseases may be complicated by eosinophilic airway obstruction.

5. a) True: this may actually be worsened by $\beta_{2}$-agonists. b) True: should be treated with airway clearance and mucolytics. c) False: any airflow obstruction is fixed. d) True: treat with $\beta_{2}$-agonists.

50. Saglani S, Payne DN, Zhu J, et al. Early detection of airway wall remodelling and eosinophilic inflammation in preschool wheezers. Am J Respir Crit Care Med 2007; 176: 858-864.

51. Stein MM, Hrusch CL, Gozdz J, et al. Innate immunity and asthma risk in Amish and Hutterite farm children. N Engl J Med 2016; 375: 411-421.

52. Bisgaard H, Hermansen MN, Buchvald F, et al. Childhood asthma after bacterial colonization of the airway in neonates. N EnglJ Med 2007; 357: 1487-1495.

53. Nieto A, Mazon A, Uixera S, et al. Bacterial mucosal immunotherapy with MV130 prevents recurrent wheezing in children: a randomized, double-blind, placebo controlled trial. Am J Respir Crit Care Med 2021; in press [https://doi. org/10.1164/rccm.202003-05200C].

54. Looijmans-van den Akker I, van Luijn K, Verheij T. Overdiagnosis of asthma in children in primary care: a retrospective analysis. BrJ Gen Pract 2016; 66: e152-e157.

55. Yang CL, Simons E, Foty RG, et al. Misdiagnosis of asthma in schoolchildren. Pediatr Pulmonol 2017; 52: 293-302.

56. Aaron S, Vandemheen KL, FitzGerald JM, et al. Reevaluation of diagnosis in adults with physician-diagnosed asthma. JAMA 2017; 317: 269-279.

57. Douwes J, Gibson P, Pekkanen J, et al. Non-eosinophilic asthma: importance and possible mechanisms. Thorax 2002; 57: 643-648.

58. Lazarus SC, Krishnan JA, King TS, et al. Mometasone or Tiotropium in mild asthma with a low sputum eosinophil level. N Engl J Med 2019; 380: 2009-2019.

59. Brusselle GG, Vanderstichele C, Jordens P, et al. Azithromycin for prevention of exacerbations in severe asthma (AZISAST): a multicentre randomised double-blind placebo-controlled trial. Thorax 2013; 68: 322-329.

60. Moore WC, Hastie AT, Li X, et al. Sputum neutrophil counts are associated with more severe asthma phenotypes using cluster analysis. J Allergy Clin Immunol. 2014; 133: 1557-1563. 
61. Andersson CK, Adams A, Nagakumar P, et al. Intra-epithelia neutrophils in paediatric severe asthma are associated with better lung function. J Allergy Clin Immunol 2017; 139 1819-1829.

62. CookJ, Beresford F, Fainardi V, et al. Managing the paediatric patient with refractory asthma: a multidisciplinary approach J Asthma Allergy 2017; 10: 123-130.

63. Lemanske RF Jr, Mauger DT, Sorkness CA, et al. Step-up therapy for children with uncontrolled asthma receiving inhaled corticosteroids. N Engl/ Med 2010; 362: 975-985.

64. Tai A, Tran $H$, Roberts $M$, et al. The association between childhood asthma and adult chronic obstructive pulmonary disease. Thorax 2014; 69: 805-810.

65. Bui DS, Lodge CJ, Burgess JA, et al. Childhood predictors of lung function trajectories and future COPD risk: a prospective cohort study from the first to the sixth decade of life. Lancet Respir Med 2018; 6: 535-544

66. Bisgaard H, Jensen SM, Bønnelykke K. Interaction between asthma and lung function growth in early life. Am J Respir Crit Care Med 2012; 185: 1183-1189.

67. Mahmoud O, Granel R, Tilling K, et al. A longitudinal study Am J Respir Crit Care Med 2018; 198: 1539-1548.

68. Agustí A, Noell G, Brugada J, et al. Lung function in early adulthood and health in later life: a transgenerational cohort analysis. Lancet Respir Med 2017; 5: 935-945.

69. Stern DA, Morgan WJ, Halonen M, et al. Wheezing and bronchia hyper-responsiveness in early childhood as predictors of newly diagnosed asthma in early adulthood: a longitudinal birthcohort study. Lancet 2008; 372: 1058-1064.

70. Svanes O, Skorge TD, Johannessen A, et al. Respiratory health in cleaners in northern europe: is susceptibility established in early life? PLoS One 2015; 10: e0131959.

71. Gibson PG, McDonald VM. Asthma-COPD overlap 2015: now we are six. Thorax 2015; 70: 683-691.

72. Pavord I, Bush A. Two lovely black eyes; Oh, what a surprise Thorax 2015; 70: 609-610.

73. Pavord ID, Lettis S, Locantore $\mathrm{N}$, et al. Blood eosinophils and inhaled corticosteroid/long-acting beta-2 agonist efficacy in COPD. Thorax 2016; 71: 118-125.

74. Pavord ID, Chanez P, Criner GJ, et al. Mepolizumab for eosinophilic chronic obstructive pulmonary disease. N Eng J Med 2017; 377: 1613-1629.

75. O’Byrne PM, Pavord ID. A golden age of asthma research. Eur RespirJ 2020; 56: 2003820

76. Holguin F, Cardet JC, Chung KF, et al. Management of severe asthma: a European Respiratory Society/American Thoracic Society guideline. Eur Respir J 2020; 55: 1900588.

77. Heaney LG, Brightling C, Menzies-Gow A, et al. Refractory asthma in the UK: cross-sectional findings from a UK multicentre registry. Thorax 2010; 65: 787-794.

78. Gibson PG, Yang IA, Upham JW, et al. Effect of azithromycin on asthma exacerbations and quality of life in adults with persistent uncontrolled asthma (AMAZES): a randomised, double-blind, placebo-controlled trial. Lancet 2017; 390: 659-668.

79. Taylor SL, Ivey KL, Gibson PG, et al. Airway abundance of Haemophilus influenzae predicts response to azithromycin in adults with persistent uncontrolled asthma. Eur Respir J 2020; 56: 2000194

80. Kermani NZ, Pavlidis S, Xie J, et al. Instability of sputum molecular phenotypes in U-BIOPRED severe asthma. Eur Respir J 2021; 57: 2001836
81. Fitzpatrick AM, Higgins M, Holguin F, et al. The molecular phenotype of severe asthma in children. J Allergy Clin Immunol 2010; 125: 851-857

82. Bossley C, Fleming L, Gupta A, et al. Pediatric severe asthma is characterized by eosinophilia and remodeling without $\mathrm{TH} 2$ cytokines. J Allergy Clin Immunol 2012; 129: 974-982.

83. Wisniewski JA, Muehling LM, Eccles JD, et al. $T_{H} 1$ signatures are present in the lower airways of children with severe asthma, regardless of allergic status. J Allergy Clin Immunol 2018; 141: 2048-2060.

84. Fleming L, Tsartsali L, Wilson N, et al. Sputum inflammatory phenotypes are not stable in children with asthma. Thorax 2012; 67: 675-681.

85. Fleming L, Tsartsali L, Wilson N, et al. Longitudinal relationship between sputum eosinophils and exhaled nitric oxide in children with asthma. Am J Respir Crit Care Med 2013; 188: 400-402.

86. Kuo CS, Pavlidis S, Loza M, et al. T-helper cell type 2 (Th2) and non-Th2 molecular phenotypes of asthma using sputum transcriptomics in U-BIOPRED. Eur Respir J 2017; 49: 1602135

87. Desai D, Newby C, Symon FA, et al. Elevated sputum interleukin-5 and submucosal eosinophilia in obese individuals with severe asthma. Am J Respir Crit Care Med 2013; 188: 657-663.

88. Peters MC, McGrath KW, Hawkins GA, et al. Plasma interleukin- 6 concentrations, metabolic dysfunction, and asthma severity: a cross-sectional analysis of two cohorts. Lancet Respir Med 2016; 4: 574-584.

89. Forno E, Weiner DJ, Mullen J, et al. Obesity and airway dysanapsis in children with and without asthma. Am J Respir Crit Care Med 2017; 195: 314-323.

90. Marchant J, Masters IB, Champion A, et al. Randomised controlled trial of amoxycillin clavulanate in children with chronic wet cough, Thorax 2012; 67: 689-693.

91. Bush A. Persistent bacterial bronchitis: time to venture beyond the umbrella. Front Pediatr 2017; 5: 264.

92. Carraro S, Piacentini G, Lusiani M, et al. Exhaled air temperature in children with bronchopulmonary dysplasia. Pediatr Pulmonol 2010; 45: 1240-1245.

93. Harju M, Keski-Nisula L, Georgiadis L, et al. The burden of childhood asthma and late preterm and early term births. J Pediatr 2014; 164: 295-299.

94. Fawke J, Lum S, Kirkby J, et al. Lung function and respiratory symptoms at 11 years in children born extremely preterm: the EPICure study. Am J Respir Crit Care Med 2010; 182: 237-245.

95. Lukkarinen $\mathrm{H}$, Pelkonen $\mathrm{A}$, Lohi J, et al. Neuroendocrine cell hyperplasia of infancy: a prospective follow-up of nine children. Arch Dis Child 2013; 98: 141-144.

96. Bhatt JM, Bush A, van Gerven M, et al. ERS statement on the multidisciplinary respiratory management of ataxia telangiectasia. Eur Respir Rev 2015; 24: 565-581.

97. Mallol J, García-Marcos L, Solé D, et al. International prevalence of recurrent wheezing during the first year of life: variability, treatment patterns and use of health resources. Thorax 2010; 65: 1004-1009.

98. Chaudry R, Rosenthal R, Bush A, et al. Reduced forced expiratory flow but not increased exhaled nitric oxide or airway responsiveness to methacholine characterises paediatric sickle cell airway disease. Thorax 2014; 69: 580-585.

99. Wallis C, Alexopoulou E, Antón-Pacheco JL, et al. ERS statement on tracheomalacia and bronchomalacia in children. Eur Respir J 2019; 54: 1900382. 